\title{
Evaluation of the Superplastic Formability of SP-Inconel 718 Superalloy
}

\author{
M.S. Yeh, C.W. Tsau, and T.H. Chuang
}

The superplastic formability of SP-Inconel 718 superalloy was evaluated using the argon blowing method. Relationships among superplastic forming parameters (forming temperature, argon pressure, and forming time) and specific dome height (dome height/workpiece diameter) were investigated, as were changes in material properties after superplastic forming. Experimental results showed the optimum forming temperature range for SP-Inconel 718 to be between 975 and $995^{\circ} \mathrm{C}$. During the superplastic forming process, $\delta$-phase precipitates formed at grain boundaries and limited the grain growth, which is considered beneficial for superplastic deformation. On the other hand, increasing the forming deformation also increased the formation of cavities, which can be attributed to the existence of niobium-rich inclusions. This degraded the superplasticity of the superalloy. Electrochemical tests showed that the corrosion resistance of SP-Inconel 718 after superplastic forming worsened because of the existence of both $\delta$-phase precipitates and niobium-rich inclusions.

\section{Keywords}

argon blowing, forming parameters, SP-Inconel 7.18 superalloy, superplastic forming

\section{Introduction}

THE NICKEL-BASE superalloys possess excellent properties, including high mechanical strength and superior corrosion and heat resistance at temperatures above those possible with ferrous alloys. However, complex components are difficult to produce using conventional mechanical techniques.

Superplastic forming is an advanced technique used to manufacture parts and components in the aerospace industry (Ref 1). Torisaka $(\operatorname{Ref} 2)$ found that Mod. IN-100 (Homogeneous Metals Company, Clayville, New York), which is hot isostatically pressed and then rolled and annealed, possesses superplasticity. The total elongation of such a material reaches $560 \%$ at a strain rate of $2.5 \times 10^{-3} / \mathrm{s}$ in the temperature range of 1323 to $1373 \mathrm{~K}(\operatorname{Ref} 2)$. Mahoney and Crooks (Ref 3) showed that wrought and powder-produced fine-grain Inconel $718^{*} \mathrm{su}-$ peralloys possess total elongations of 500 and $150 \%$, respectively.

In this work, the superplastic formability of SP-Inconel 718 superalloy has been further studied using an argon blowing method. In addition, changes in material microstructure and properties after superplastic forming were investigated.

For the superplastic forming of a thin sheet, Ragab (Ref 4) has shown that the distribution of the wall thickness is

$$
\frac{S}{S_{0}}=\left[\frac{1+\sigma Y_{\mathrm{p}}}{d^{2}}\right]^{-2}
$$

where $S$ is the instantaneous thickness of the sheet, $S_{0}$ is the initial thickness of the sheet, $\sigma$ is the height of the bulge annulus

*Inconel 718 is a tradename of INCO Alloys International, Inc.

M.S. Yeh, C.W. Tsau, and T.H. Chuang, Institute of Materials Science and Engineering, National Taiwan University, Taipei, Taiwan, R.O.C. or section during free bulging, $Y_{\mathrm{p}}$ is the height of the bulge during free bulging, and $d$ is the die aperture radius or half-width (Fig. 1). In this work, results calculated from the theoretical models of Ragab will be compared with experimental results for SP-Inconel 718 superalloy.

Cozar and Pineau (Ref 5) have shown that Inconel 718 superalloy possesses an austenite matrix. The primary age hardening phase is $\mathrm{Ni}_{3} \mathrm{Nb}\left(\gamma^{\prime \prime}\right)$, which is the ordered body-centered tetragonal structure. The $\delta$-phase precipitate $\left(\mathrm{Ni}_{3} \mathrm{Nb}\right)$ with an orthorhombic structure also exists in Inconel 718 superalloy. Because Inconel 718 superalloy is a precipitate-hardening material, the size, quantity, and types of precipitate will influence its properties. In various studies, the $\delta$-phase precipitate formed at the grain boundaries or in the matrix influenced the fatigue (Ref 6), corrosion ( $\operatorname{Ref} 7$ ), and hot-working (Ref 8) properties of Inconel 718 superalloy. In addition to the precipitate, niobium-rich inclusions were formed in this material. This evaluation of the superplasticity of SP-Inconel 718 superalloy will focus on the effect of precipitates and inclusions.

\section{Experimental Procedure}

The material used in this study was SP-Inconel 718 superalloy, which was fabricated by INCO Alloys International, Inc. (Huntington, West Virginia) in the form of $1.3 \mathrm{~mm}(0.05 \mathrm{in}$. thick plate. The chemical composition of the superalloy is given in Table 1 .

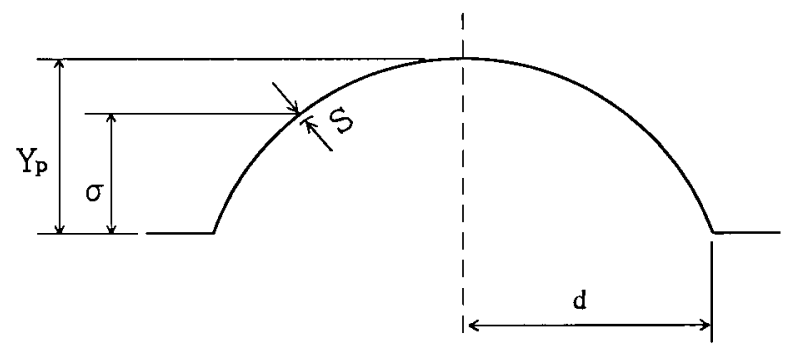

Fig. 1 Geometry of deformation during free bulging of circular sheet 
Specimens $75 \mathrm{~mm}$ in diameter were cut from the sheet. To evaluate superplastic formability, a testing instrument was developed (Fig. 2). The amount of specimen deformation was measured directly by a linear variable differential transformer (LVDT) during the forming process. Figure 3 shows a typical specimen after superplastic deformation. The specimen was then cut along the centerline for metallurgical analysis. Microstructure was observed by optical microscopy and scanning electron microscopy (SEM), and microhardness was measured.

Corrosion properties were investigated at room temperature in $3.5 \% \mathrm{NaCl}$ solution using an EG\&G potentiostat (mode, $273 \mathrm{~A}$ ). Corrosion specimens $\left(1 \mathrm{~cm}^{2}\right)$ were cut from the superplastically deformed specimen at different positions. Test specimens were ground with 600-grit $\mathrm{SiC}$ paper and then cleaned in acetone for 5 min. After test specimens were immersed in $3.5 \% \mathrm{NaCl}$ solution, corrosion potential ( $\Phi_{\text {con }}$ ) was measured with respect to a saturated calomel electrode (SCE). Cyclic polarization testing determined the corrosion properties of SP-Inconel 718 superalloy after superplastic deformation.

\section{Results and Discussion}

\subsection{Superplastic Formability}

The specific dome heights (dome height/workpiece diameter, $H / D$ ) of the specimens after superplastic forming at various
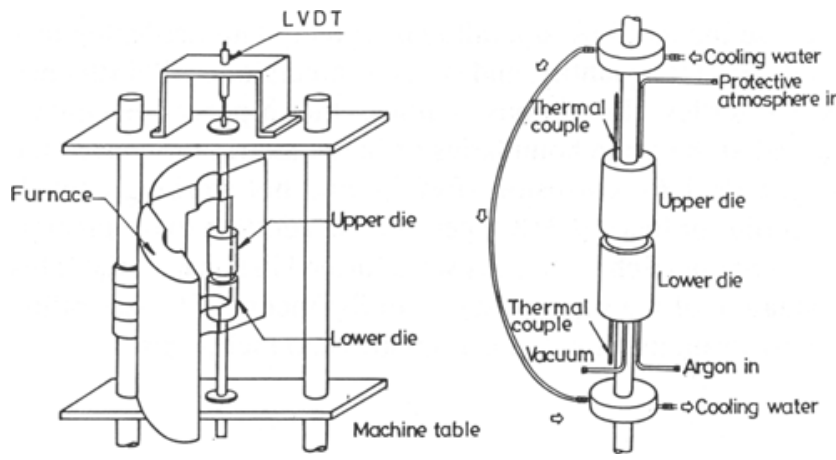

Fig. 2 Apparatus used for superplastic forming

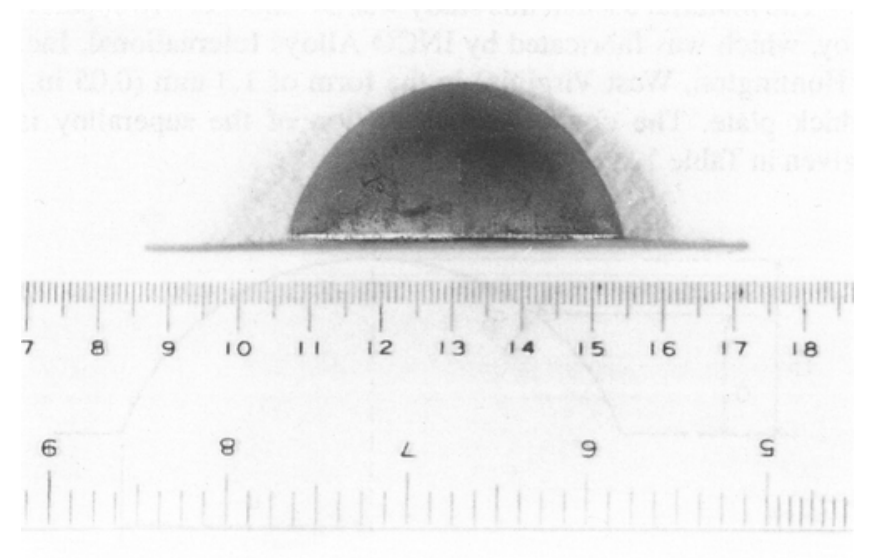

Fig. 3 Typical superplastically deformed specimen temperatures under various argon pressures are shown in Fig. 4 as a function of blowing time. At temperatures lower than 950 ${ }^{\circ} \mathrm{C}$, the forming rate becomes very slow. Also, the pressure required for forming must be higher than $400 \mathrm{psi}$ for this material. This is higher than the pressure needed for superplastically blowing a Ti-6Al-4V alloy, which is about 300 psi. The optimum superplastic forming conditions for SP-Inconel 718 superalloy are a temperature ranging from 975 to $995^{\circ} \mathrm{C}$ and a pressure above $400 \mathrm{psi}$. Under such conditions, a specimen can be superplastically formed to a dome height of about half its diameter in $100 \mathrm{~min}$.

Figure 5 shows that the specific thickness (thickness of formed specimen/thickness of original plate, $S / S_{0}$ ) varies with workpiece position. The curves obtained from the models of Ragab (Ref 4 ) are also shown in Fig. 5 by a solid line.

Microhardness data for superplastically deformed specimens are given in Table 2. The microhardness of the as-received sheet was about $270 \mathrm{HV}$. At temperatures greater than $995^{\circ} \mathrm{C}$, microhardness decreased with forming time-because $\delta$-phase precipitates dissolved and grains grew. However, microhardness increased with forming time when forming temperatures were lower than $995{ }^{\circ} \mathrm{C}$. High microhardness for deformed specimens is due to precipitation-strengthening phases. Moreover, microhardness varied with deformed specimen position. In general, the greatest superplastic strain position had the lowes! microhardness. Since many cavities nucleated and interlinked at that position, its mechanical properties were drastically affected.

\subsection{Microstructure}

The microstructure of as-received SP-Inconel 718 superalloy possessed equiaxed fine grains $(<10 \mu \mathrm{m})$ with some inclusion particles in the matrix (Fig. 6a). Energy-dispersive $x$-ray (EDX) spectrum analysis showed these particles to be niobium rich (Fig. 6b). After superplastic forming at $985^{\circ} \mathrm{C}$ under an argon pressure of $350 \mathrm{psi}$, the grains of material grew slightly (Fig. 7). It appeared that the stress assisted a dynamic grain growth. Sakai and Jones ( $\operatorname{Ref} 9$ ) postulated that this process involved the migration of high-angle boundaries and the elimination of a large number of dislocations. Furthermore, Srinivasan

Table 1 Chemical composition of SP-Inconel 718 superalloy

\begin{tabular}{lc}
\hline Element & Percentage \\
\hline Carbon & 0.03 \\
Manganese & 0.08 \\
Iron & 17.9 \\
Silicon & 0.11 \\
Copper & 0.09 \\
Nickel & 53.85 \\
Chromium & 18.26 \\
Aluminum & 0.53 \\
Titanium & 1.06 \\
Cobalt & 0.15 \\
Molybdenum & 3.01 \\
Phosphorus & 0.011 \\
Boron & 0.002 \\
Sulfur & 0.001 \\
Niobium + tantalum & 4.92 \\
\hline
\end{tabular}


and Prasad (Ref 8) confirmed that Inconel 718 exhibited two domains of dynamic recrystallization. At a temperature of 950 ${ }^{\circ} \mathrm{C}$ and a strain rate of $0.001 \mathrm{~s}^{-1}$, recrystallization was nucleated by the $\delta$ precipitation and a fine grain size was produced.

It was also found that many precipitates exist at the grain boundaries (Fig. 8). Comparing the bulk alloy with the precipitates, EDX analysis showed that the precipitates are rich in niobium (Fig. 9). The time-temperature-precipitation diagram for Inconel 718 superalloy (Ref 5) shows that the $\delta$-precipitation phase is present at grain boundaries or appears as Widmanstätten plates in the matrix ( $\operatorname{Ref} 3$ ). With superplastic forming at
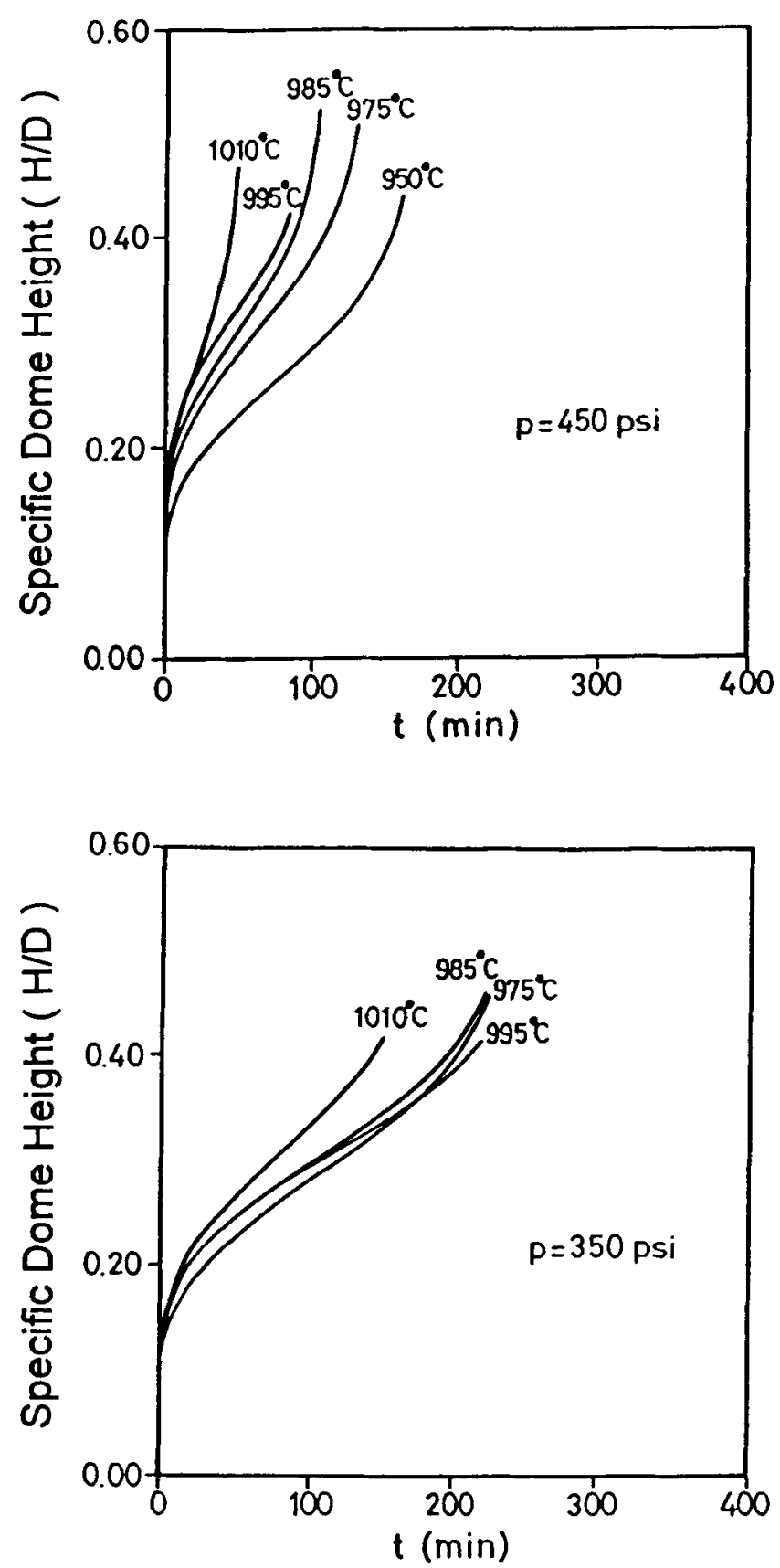

$985^{\circ} \mathrm{C}$, which is below the $\delta$ dissolution temperature $\left(995^{\circ} \mathrm{C}\right)$, these precipitates pin the grain boundary and inhibit the grain growth of Inconel 718 during the superplastic forming. However, heating to $1010^{\circ} \mathrm{C}$ permits grain growth, since the grainsize controller ( $\delta$ phase) is lost. Figure 10 shows the microstructure of SP-Inconel 718 after $1010^{\circ} \mathrm{C} / 1 \mathrm{~h}$ solution treatment. The grains grow drastically $(>50 \mu \mathrm{m})$. Comparison of Fig. 7(a) with Fig. 10 shows that precipitates can inhibit grain growth. Since a fine and stable grain size is required for superplasticity, the $\delta$-phase precipitates in SP-Inconel 718 are beneficial to its superplastic forming behavior.
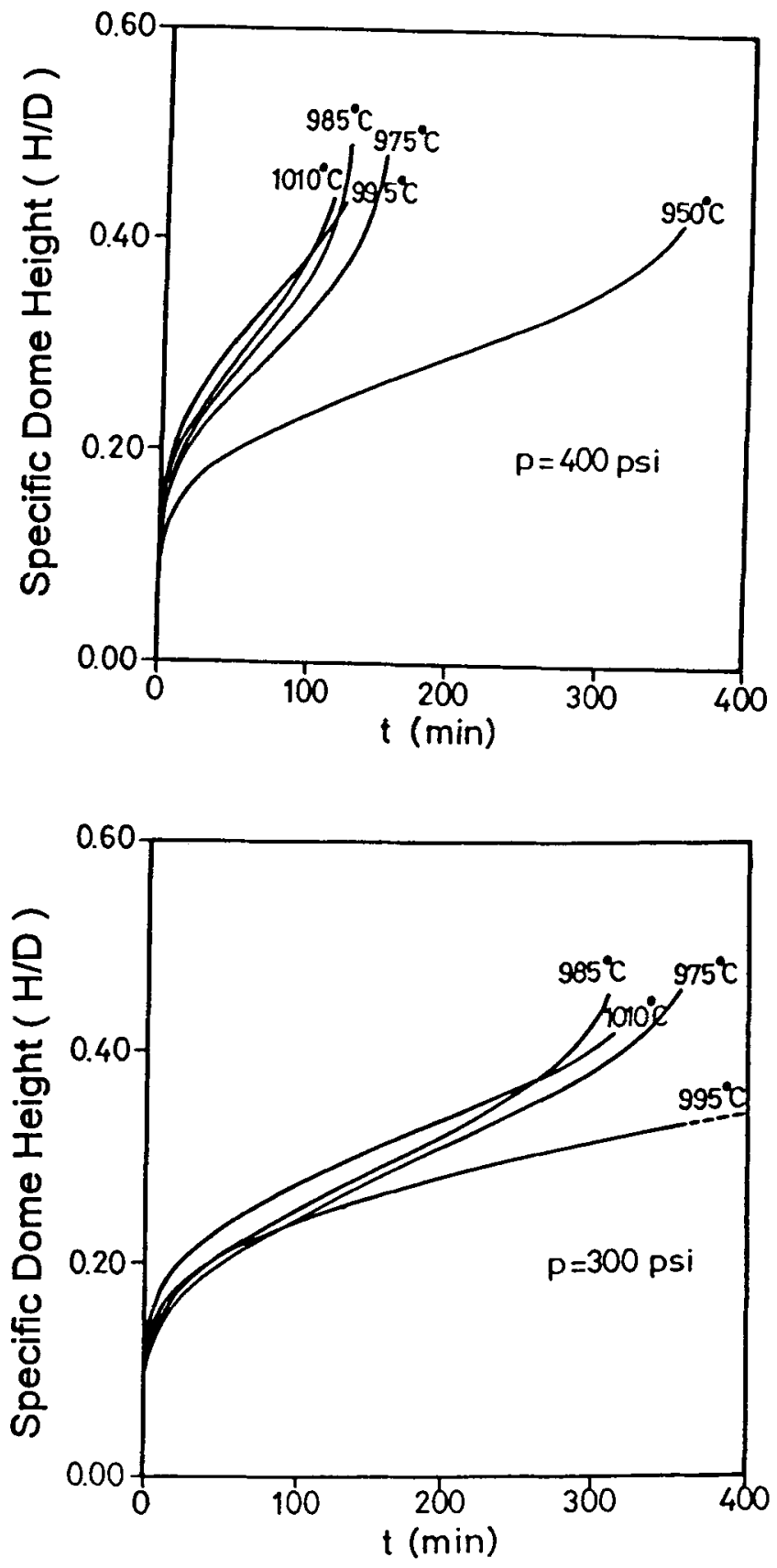

Fig. 4 Relationships between specific forming height (forming height/workpiece diameter, $H / D$ ) and forming time ( $t$ ) for superplastic forming at different temperatures and argon pressures 

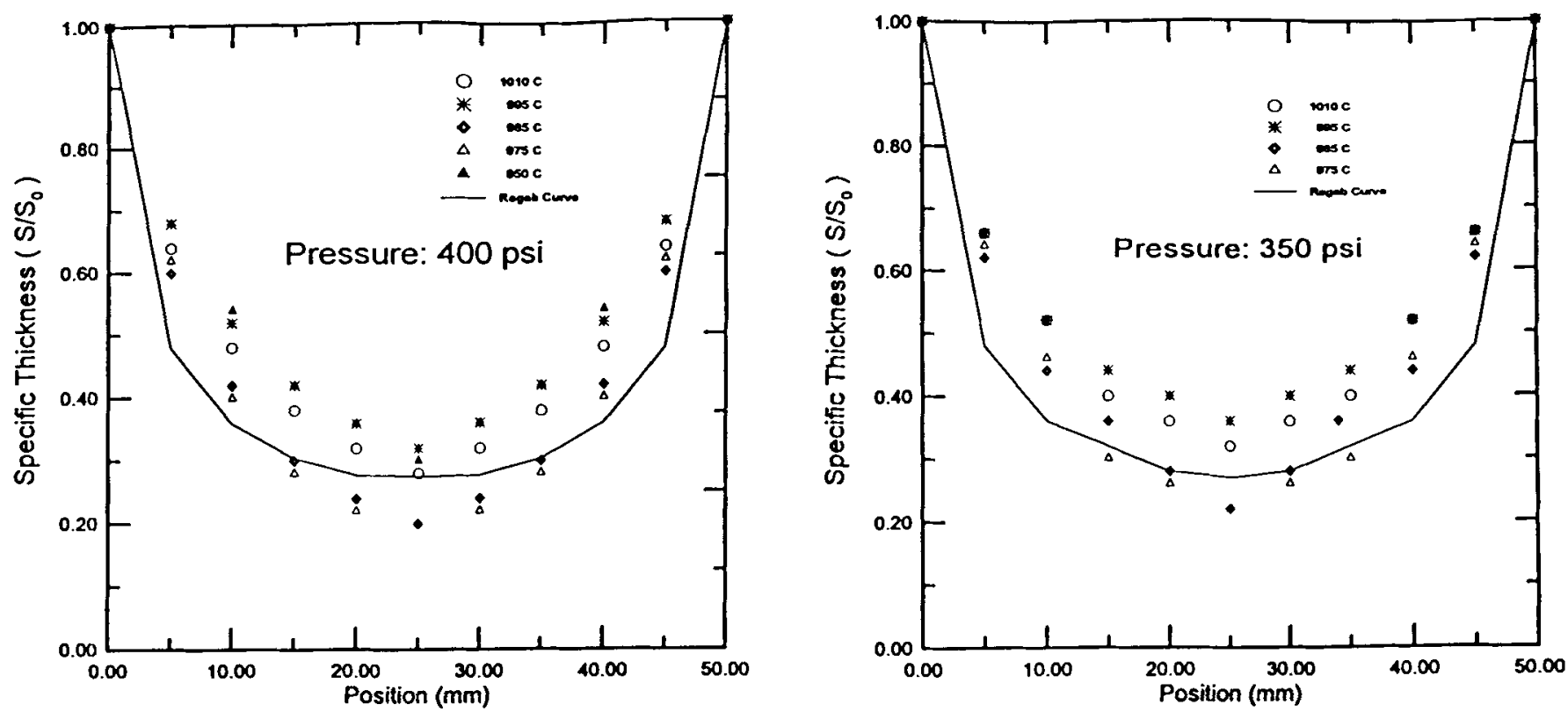

Fig. 5 Specific thickness $\left(S / S_{0}\right)$ distribution after superplastic forming under various conditions

Table 2 Microhardness of SP-Inconel 718 superalloy after superplastic forming under various conditions Positions A, B, C, and D are shown in Fig. 7

\begin{tabular}{|c|c|c|c|c|c|c|}
\hline \multirow{2}{*}{$\begin{array}{l}\text { Temperature, } \\
{ }^{\circ} \mathrm{C}\end{array}$} & \multirow{2}{*}{$\begin{array}{c}\text { Pressure, } \\
\text { psi }\end{array}$} & \multicolumn{5}{|c|}{ Microhardness, HV } \\
\hline & & $\mathbf{A}$ & $\mathbf{B}$ & $\mathbf{C}$ & D & Average \\
\hline \multirow[t]{4}{*}{1010} & 450 & 314.6 & 316.2 & 309.8 & 286.2 & 306.7 \\
\hline & 400 & 281.0 & 279.6 & 276.8 & 279.8 & 279.3 \\
\hline & 350 & 258.4 & 256.6 & 257.0 & 258.2 & 257.6 \\
\hline & 300 & 222.4 & 224.8 & 225.8 & 225.0 & 224.5 \\
\hline \multirow[t]{4}{*}{995} & 450 & 266.0 & 253.2 & 250.0 & 247.4 & 254.2 \\
\hline & 400 & 262.6 & 259.4 & 261.6 & 256.8 & 260.1 \\
\hline & 350 & 259.0 & 260.6 & 259.6 & 258.2 & 259.4 \\
\hline & 300 & 236.8 & 232.8 & 232.4 & 234.6 & 234.2 \\
\hline \multirow[t]{4}{*}{985} & 450 & 283.4 & 281.6 & 266.6 & 228.6 & 265.1 \\
\hline & 400 & 279.2 & 282.4 & 258.4 & 249.6 & 267.4 \\
\hline & 350 & 278.8 & 282.4 & 256.6 & 251.2 & 267.3 \\
\hline & 300 & 286.2 & 283.0 & 254.0 & 247.8 & 267.8 \\
\hline \multirow[t]{4}{*}{975} & 450 & 284.6 & 288.2 & 259.6 & 258.4 & 272.7 \\
\hline & 400 & 360.2 & 360.0 & 334.8 & 302.8 & 339.5 \\
\hline & 350 & 356.4 & 358.0 & 331.4 & 292.0 & 334.5 \\
\hline & 300 & 358.4 & 358.8 & 350.6 & 339.2 & 351.8 \\
\hline \multirow[t]{2}{*}{950} & 450 & 287.4 & 286.8 & 269.0 & 252.4 & 273.9 \\
\hline & 400 & 312.4 & 315.6 & 318.0 & 314.6 & 315.2 \\
\hline
\end{tabular}

When superplastic strain was increased, cavities nucleated at grain triple points and at the grain-boundary particles, and cavities grew and interlinked. Figure 11 illustrates the cavities associated with the niobium-rich inclusions. Mahoney and Crooks (Ref 3 ) also found that the cavities were associated with the niobium carbide stringers and when tested in the longitudinal orientation were parallel to the stress direction. It has been suggested that irregular inclusions limited grain-boundary sliding and that cavities were nucleated at the inclusion/matrix interfaces (Ref 10). In this case, the niobium-rich inclusions are harmful to the superplastic forming of SP Inconel 718.

\subsection{Corrosion Test}

Figure 12 shows the polarization curves of SP-Inconel 718 in $3.5 \% \mathrm{NaCl}$ solution. The corrosion properties are given in
Table 3 Corrosion data for SP-Inconel 718 superalloy in $3.5 \% \mathrm{NaCl}$ solution

\begin{tabular}{lccc}
\hline Condition & $\begin{array}{c}\text { Corrosion } \\
\text { potential } \\
\left(\boldsymbol{\Phi}_{\text {corr }}\right), \mathbf{m V}\end{array}$ & $\begin{array}{c}\text { Breakdown } \\
\text { potential } \\
\left(\Phi_{\mathbf{b}}\right), \mathbf{m V}\end{array}$ & $\begin{array}{c}\text { Corrosion } \\
\text { current density } \\
\left(\boldsymbol{i}_{\mathbf{c o r r}}\right), \mathbf{n A} / \mathbf{c m}^{\mathbf{2}}\end{array}$ \\
\hline $\begin{array}{l}\text { As-received } \\
\text { Superplastically formed } \\
\left(985^{\circ} \mathrm{C}, 350 \mathrm{psi}, 1 \mathrm{~h}\right)\end{array}$ & -150 & 998 & $\mathbf{1 8 . 1}$ \\
$\quad($ see Fig. 7) & & & \\
Position A & -151 & 959 & \\
Position C & -153 & 343 & 33.2 \\
Position D & -157 & 142 & 40.1 \\
\hline
\end{tabular}

Table 3. The corrosion potential of the as-received material was about $-150 \mathrm{mV}(\mathrm{SCE})$, and its corrosion rate was about 18.1 


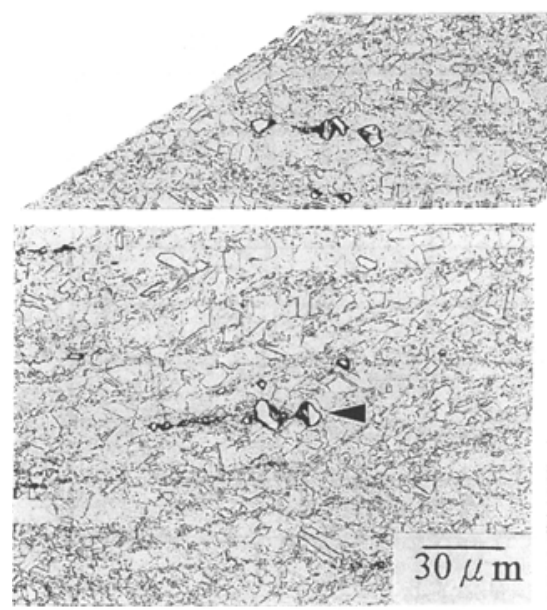

(a)

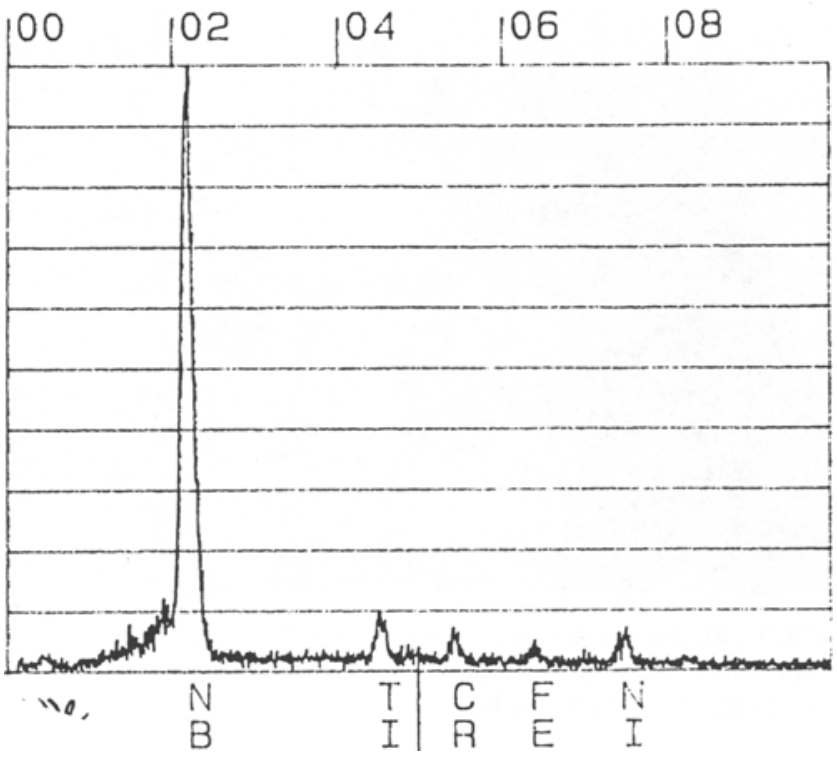

(b)

Fig. 6 (a) Microstructure of as-received SP-Inconel 718 superalloy. (b) EDX spectrum for the inclusion particle

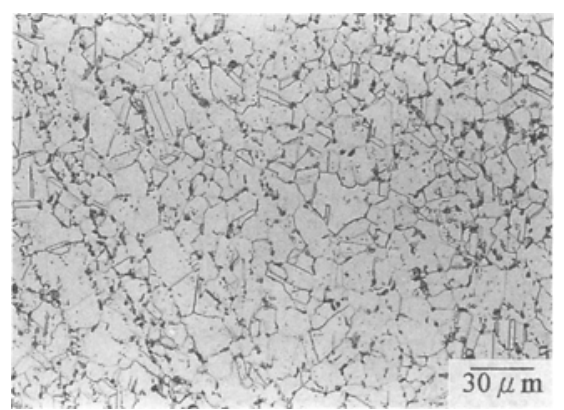

(a)

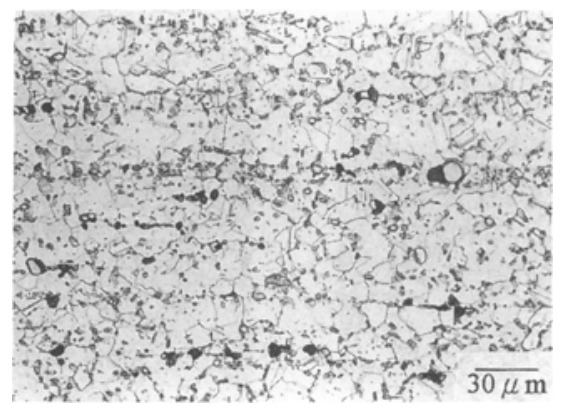

(b)

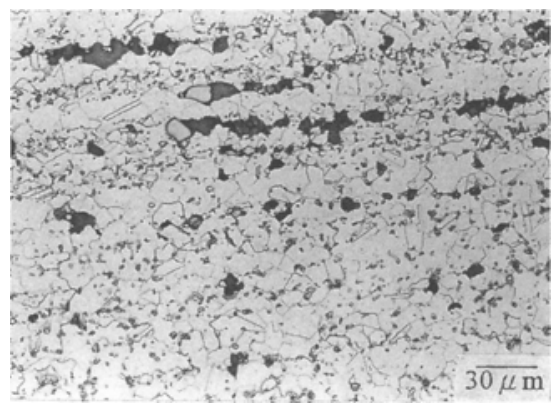

(c)
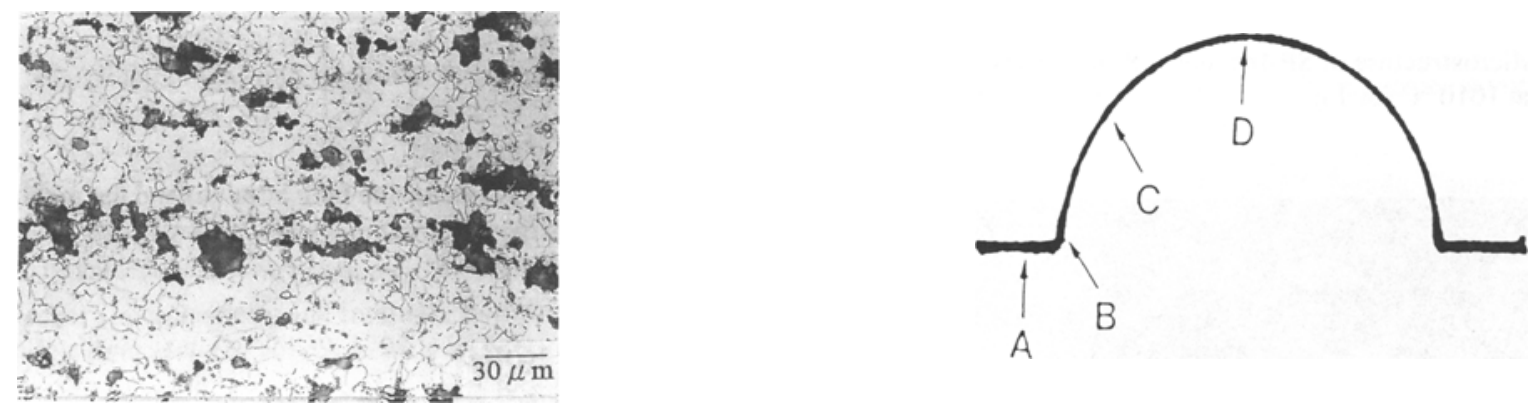

(d)

Fig. 7 Microstructure of SP-Inconel 718 superalloy after superplastic forming at $985^{\circ} \mathrm{C}$ for 205 min under argon pressure of 350 psi. (a), (b), (c), and (d) taken from workpiece cross-sectional positions A, B, C, and D, respectively

$\mathrm{nA} / \mathrm{cm}^{2}$. After superplastic forming at $985^{\circ} \mathrm{C}$ for $1 \mathrm{~h}$ under an argon pressure of $350 \mathrm{psi}$, the corrosion properties changed with the position of the superplastically deformed dome. The breakdown potential for cross-sectional position A of the workpiece was more active than the as-received material, because many $\delta$-phase precipitates were found at the grain boundaries, causing intercrystalline corrosion (Fig. 13). Cross-sectional position $D$ had the greatest superplastic strain. In this case, cavities were interlinked and more fresh area was created (Fig. 14a). The corrosion rate was $40.1 \mathrm{nA} / \mathrm{cm}^{2}$, and the breakdown potential was $142 \mathrm{mV}$ (SCE). Figure 14(b) shows that corrosion selectively attacked the cavities and that precipitates exist at the grain boundaries. Corrosion resistance decreased with increased superplastic forming. 


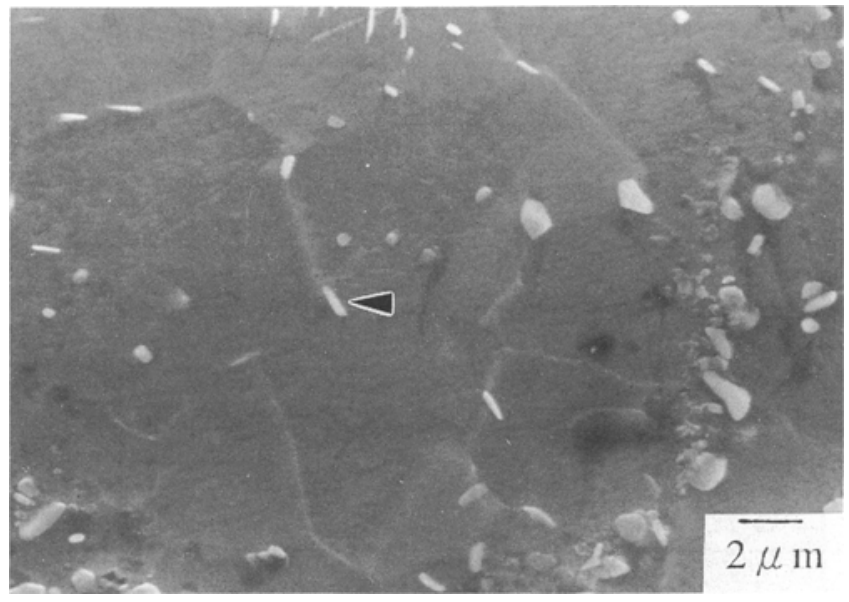

Fig. 8 SEM microstructure of SP-Inconel 718 superalloy after superplastic forming at $985^{\circ} \mathrm{C}$ for 205 min under argon pressure of 350 psi. Position A (see Fig. 7)

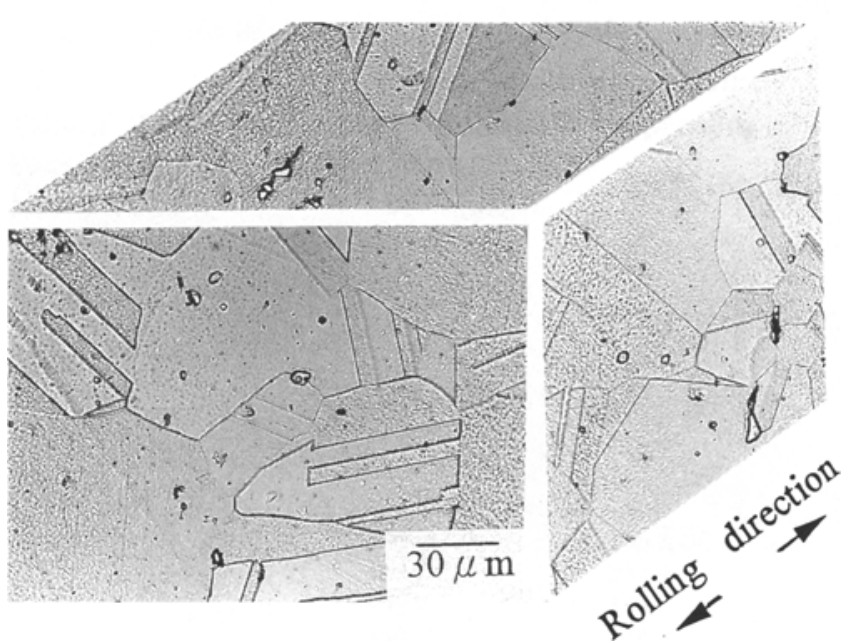

Fig. 10 Microstructure of SP-Inconel 718 superalloy after heat treatment at $1010^{\circ} \mathrm{C}$ for $1 \mathrm{~h}$

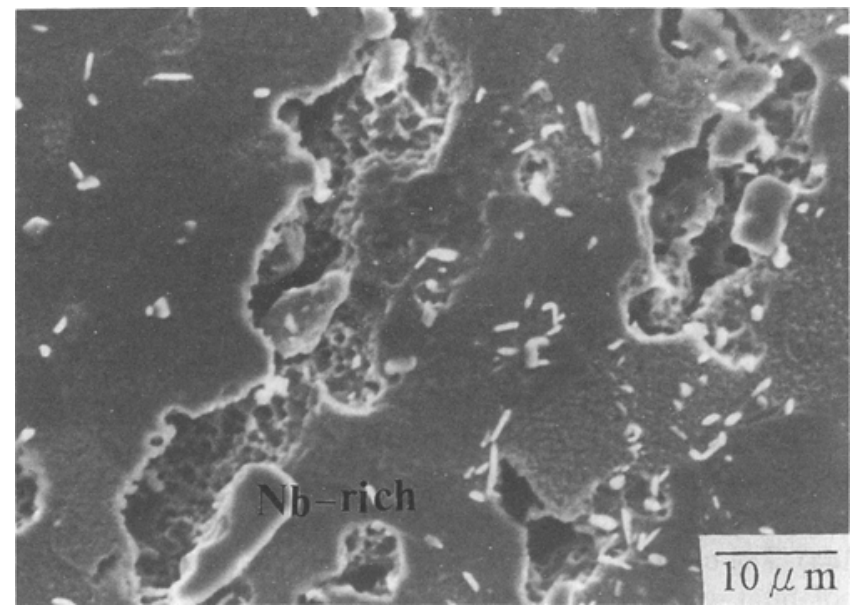

Fig. 11 SEM microstructure of SP-Inconel 718 superalloy after superplastic forming at $985^{\circ} \mathrm{C}$ for 205 min under argon pressure of $350 \mathrm{psi}$

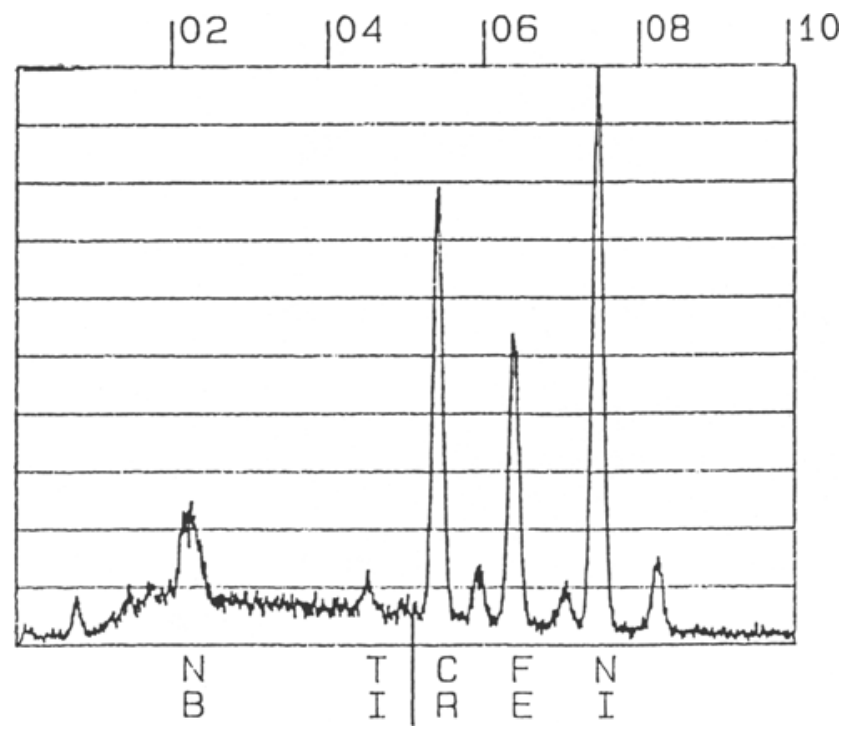

(a)

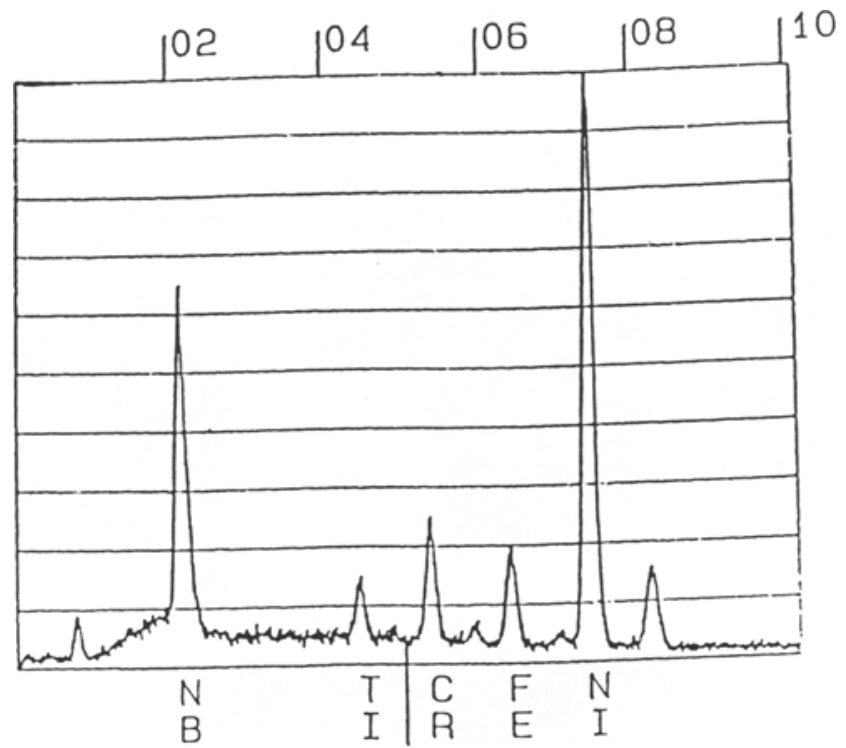

(b)

Fig. 9 EDX spectra for the bulk alloy (a) and the precipitates (b) after superplastic forming at $985^{\circ} \mathrm{C}$ for 205 min under argon pressure of $350 \mathrm{psi}$

\section{Conclusions}

Experimental results show the optimum superplastic forming temperature range of SP-Inconel 718 superalloy to be between 975 and $995{ }^{\circ} \mathrm{C}$. During the forming process, the material maintains a fine grain size, which is the result of the pinning effect of many niobium precipitates on grain growth.

After superplastic forming, cavities, which increase with the amount of forming, were found. Cavity formation is attributed to niobium-rich inclusions in the grains. The corrosion resistance of the superplastically deformed dome decreases due to the formation of niobium precipitates at the grain boundaries and the formation of cavities that expose more fresh area to the corrosion environment. 


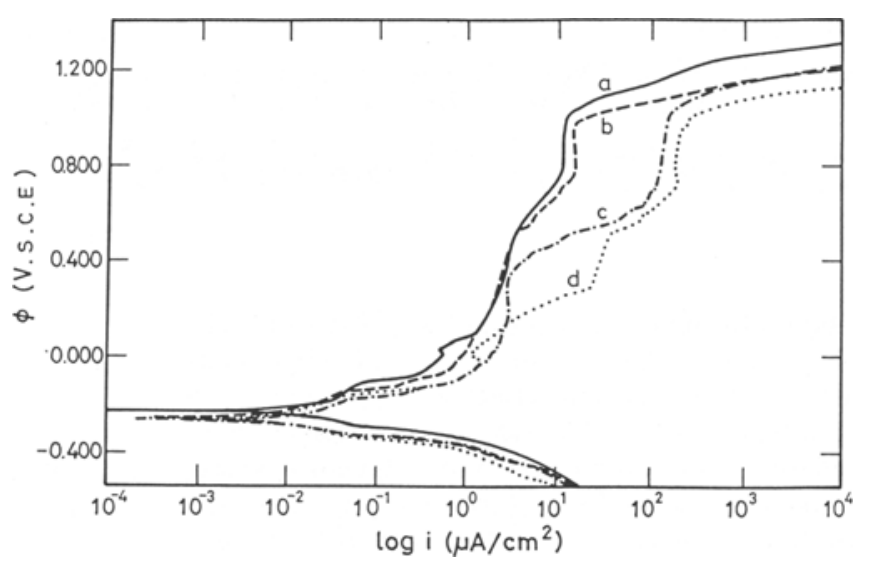

Fig. 12 Corrosion polarization curves for SP-Inconel 718 superalloy in $3.5 \% \mathrm{NaCl}$ solution. a, As-received. b, c, and d, After superplastic forming at $985^{\circ} \mathrm{C}$ for $1 \mathrm{~h}$ under argon pressure of 350 psi for workpiece cross-sectional positions A, C, and D, respectively (see Fig. 7)

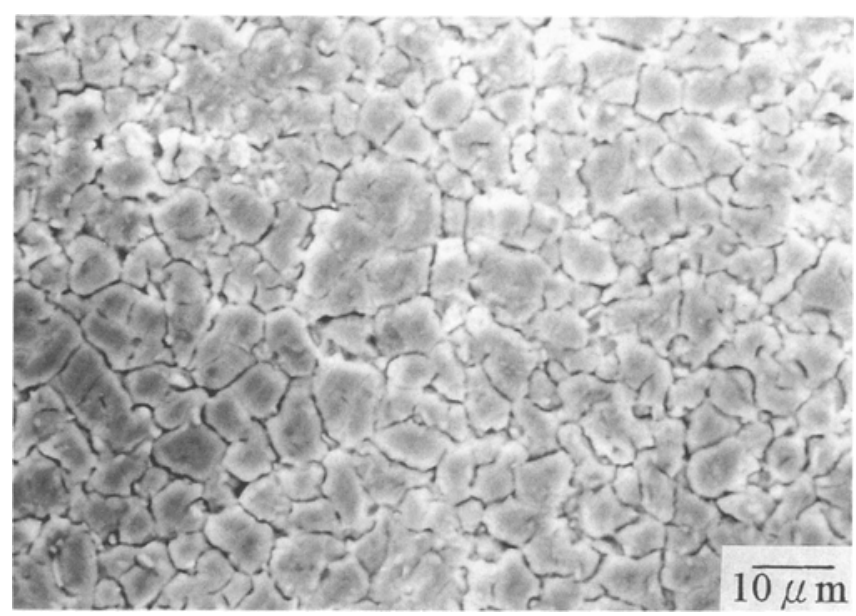

(a)

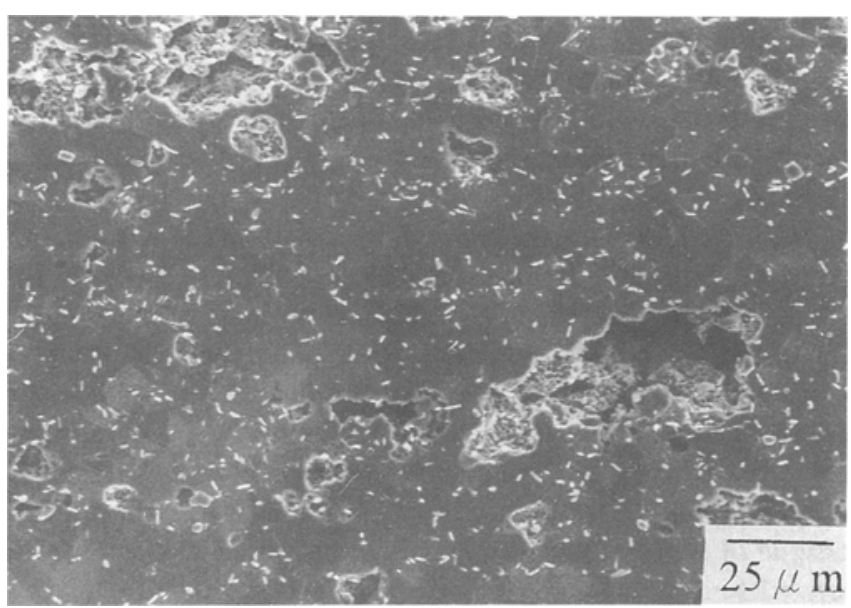

Fig. 13 SEM microstructure of SP-Inconel 718 superalloy in $3.5 \% \mathrm{NaCl}$ solution showing intercrystalline corrosion

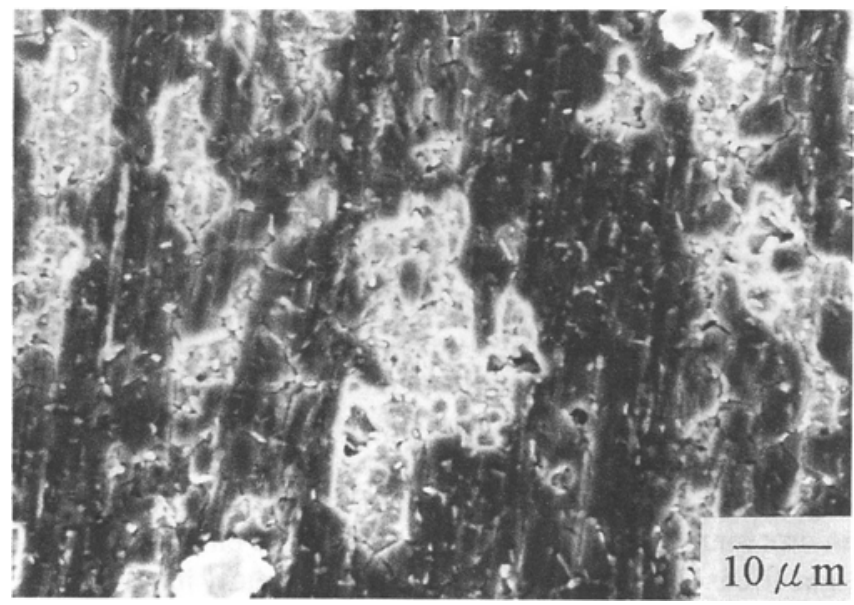

(b)

Fig. 14 SEM fractographs of SP-Inconel 718 superalloy in $3.5 \% \mathrm{NaCl}$ solution. (a) Before corrosion test. (b) After corrosion test

\section{References}

1. C.H. Hamilton and G.W. Stacher, Superplastic Forming of Ti6Al-4V Beam Frames, Met. Prog., Vol 109 (No. 3), 1976, p 34

2. Y. Torisaka, Superplasticity and Internal Friction of Nickel-Base Superalloy, Acta Metall., Vol 39, 1991, p 937

3. M.W. Mahoney and R. Crooks, Superplastic Forming of Inconel 718, Superplasticity in Aerospace, H.C. Heikkenen and T.R. McNelley, Ed., TMS, 1988, p 331

4. A.R. Ragab, Thermoforming of Superplastic Sheet in Shaped Dies, Met. Technol., Vol 10, 1983, p 340

5. R. Cozar and A. Pineau, Morphology of $\gamma^{\prime}$ and $\gamma^{\prime \prime}$ Precipitates and Thermal Stability of Inconel 718 Type Alloys, Metall. Trans., Vol 4, 1973, p 47
6. M. Chang, A.K. Koul, P. Au, and T. Terada, Damage Tolerance of Wrought Alloy $718 \mathrm{Ni}$-Fe-Base Superalloy, J. Mater. Eng. Perform., Vol 3, 1994, p 356

7. J. Prybylowski and R. Ballinger, Influence of Microstructure on the Environmentally Assisted Cracking of Inconel 718, Corrosion, Vol 43, 1987; $\mathrm{p} 111$

8. N. Srinivasan and Y.V.R.K. Prasad, Microstructural Control in Hot Working of IN-718 Superalloy Using Processing Map, Metall. Trans., Vol 25, 1994, p 2275

9. T. Sakai and J.J. Jonas, Dynamic Recrystallization: Mechanical and Microstructural Considerations, Acta Metall., Vol 32, 1984, p 189

10. J. Pilling and N. Ridley, Cavitation and Fracture, Superplasticity in Crystalline Solids, Institute of Metals, London, 1989, p 102 